MARUYAMA, W.I; BRAZ, L.T.; CECÍLIO FILHO, A.B. Condução de melão rendilhado sob cultivo protegido. Horticultura Brasileira, Brasília, v. 18, n. 3, p. $175-178$, novembro 2.000 .

\title{
Condução de melão rendilhado sob cultivo protegido.
}

\author{
Wilson Itamar Maruyama; Leila Trevizan Braz; Arthur Bernardes Cecílio Filho \\ FCAV - UNESP, Via de Acesso Prof. Dr. Paulo Donato Castellane Km 5, 14.870-000 Jaboticabal - SP. e-mail: maruyama@fcav.unesp.br, \\ leilatb@fcav.unesp.br, rutra@fcav.unesp.br
}

\section{RESUMO}

Estudou-se o comportamento de dois híbridos de melão rendilhado (Bônus $\mathrm{n}^{\mathrm{o}} 2$ - polpa verde e D. Carlos - polpa salmão), conduzidos com uma ou duas hastes, em três diferentes posições de fixação dos frutos $\left(5^{\circ}\right.$ ao $8^{\circ}, 9^{\circ}$ ao $11^{\circ}$ e $12^{\circ}$ ao $15^{\circ}$ nó). Adotou-se delineamento de blocos ao acaso, com três repetições, no esquema fatorial 2 X 2 X 3 . O experimento foi conduzido no segundo semestre de 1998, em região de clima Cwa. Realizou-se plantio em fileira única, com espaçamento de $1,25 \mathrm{~m}$ entre linhas e $0,25 \mathrm{~m}$ entre plantas, com irrigação por gotejamento, em casa de vegetação tipo arco, com laterais abertas, sendo as plantas conduzidas alternadamente uma para cada lado, em forma de V; adotou-se o limite de dois frutos por planta. Ocorreram interações entre híbridos e posições de fixação do fruto para altura de fixação do fruto, entre híbrido e sistema de condução para conteúdo de sólidos solúveis, entre sistema de condução e posição de fixação do fruto para número médio de frutos por planta e produção total de frutos por planta. Plantas conduzidas com duas hastes apresentaram maior distância entre o solo e o nó de fixação do fruto $(55,17 \mathrm{~cm})$, em relação às com uma haste $(39,50 \mathrm{~cm})$ para os dois híbridos. O híbrido Bônus $\mathrm{n}^{\circ} 2$ apresentou maior quantidade de matéria seca por planta, na floração $(22,61 \mathrm{~g})$ e na colheita $(74,34 \mathrm{~g})$, maior área foliar por planta, na floração $\left(0,3613 \mathrm{~m}^{2}\right)$ e colheita $\left(0,7701 \mathrm{~m}^{2}\right)$, maior número de frutos por planta $(1,15)$, maior produção total de frutos por planta $(1,18 \mathrm{~kg})$, e maior conteúdo de sólidos solúveis $(15,0 \%)$ em relação a 'D. Carlos' $\left(16,39 \mathrm{~g}, 52,48 \mathrm{~g}, 0,2550 \mathrm{~m}^{2}, 0,6094 \mathrm{~m}^{2}, 0,78\right.$ frutos, 0,848 $\mathrm{kg} /$ fruto, e $11,3 \%$, respectivamente). O híbrido D. Carlos, conduzido com duas hastes, apresentou maior conteúdo de sólidos solúveis $(12,0 \%)$ em relação a uma haste $(10,5 \%)$, o que não foi observado para 'Bônus $n^{\circ} 2$ '. A posição de fixação do fruto não influenciou no conteúdo de sólidos solúveis (12,9 a 13,3\%), na massa média do fruto $(1,050$ a $1,090 \mathrm{~kg})$ e no número médio de frutos por planta $(1,05 \mathrm{a}$ $1,30)$. Entretanto, para a produção total por planta, no sistema de condução com uma ou duas hastes, as posições acima do $9^{\circ}$ nó até o $15^{\circ}$ nó apresentaram maior produção (1,123 a 1,352 kg/planta). 'D. Carlos' mostrou-se mais precoce (81 dias em média) em relação a 'Bônus $n^{\circ}$ 2' (98 dias em média).

Palavras-chave: Cucumis melo, poda, posição de fixação, sistema de condução, produção.

\section{ABSTRACT}

Net melon fruit conduction in greenhouse.

There was studied the behavior of two hybrids with netted skin (Bônus $\mathrm{n}^{\circ} 2$ - green flesh and D. Carlos - orange flesh), conducted with two training methods (one or two stems) and three fruit setting positions ( $5^{\text {th }}$ until $8^{\text {th }}, 9^{\text {th }}$ until $11^{\text {th }}$ and $12^{\text {th }}$ until $15^{\text {th }}$ nodes). The experimental design was of randomized blocks in a factorial arrangement $2 \times 2 \times 3$, and three replications. It was conducted at the second semester of 1998 under a Cwa climate. Single row plots with plants spaced $1,25 \mathrm{~m}$ between lines and $0,25 \mathrm{~m}$ between plants were dripping irrigated in a greenhouse of arc type, with open side. Plant stems were conducted in an alternated way, one to the left and the other to the right, in a $\mathrm{V}$ form, with maximum of two fruits per plant. There were observed interactions between the hybrids and the height of the fruit setting node; between hybrids and the training methods for soluble solids concentration (SSC); between training methods and the fruit setting position for number of fruits per plant and total yield per plant. Plants conducted with two stems presented higher fruit set node $(55.17 \mathrm{~cm})$ when compared to the plants conducted with only one stem $(39.50 \mathrm{~cm})$. The Bônus $\mathrm{n}^{\circ} 2$ hybrid presented higher values of dry matter per plant at flowering (22.61 $\mathrm{g} /$ plant) and at harvest (74.34 g/plant), higher leaf area at flowering $\left(3,613.83 \mathrm{~cm}^{2} /\right.$ plant $)$ and at harvest $\left(7,701.76 \mathrm{~cm}^{2} /\right.$ plant $)$, more fruits per plant (1.15), higher total production of fruits per plant $(1.18 \mathrm{~kg})$ and SSC (15.0\%) when compared to D. Carlos hybrid (16.39 g/plant; $52.48 \mathrm{~g} /$ plant; $0.2550 \mathrm{~m}^{2} /$ plant; $0.6094 \mathrm{~m}^{2} /$ plant; 0.78 fruit; 0.848 $\mathrm{kg} /$ fruit and $11.3 \%$, respectively). Plants of ' $\mathrm{D}$. Carlos' conducted with two stems presented higher SSC (12.0\%) than those conducted with one stem $(10.5 \%)$. The fruit set position had not influence on the SSC (12.9 to $13.3 \%)$ and average fruit weight (1.050 to 1.090 $\mathrm{Kg}$ ), however the higher number of fruits per plant (1.05 to 1.30) and higher yield of 1.123 to $1.352 \mathrm{~kg}$ per plant were observed in the $9^{\text {th }}-11^{\text {th }}$ and $12^{\text {th }}-15^{\text {th }}$ nodes. 'D. Carlos' was more precocious $(81$

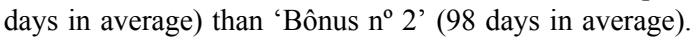

Keywords: Cucumis melo, pruning, fruit setting, training, production.

(Aceito para publicação em 17 de agosto de 2.000) 
$\mathrm{D}^{\mathrm{s}}$ esde longa data, o melão rendilhado é conhecido e cultivado em vários países como Japão, França, Estados Unidos, sendo que o seu consumo tem aumentado expressivamente nos últimos 20 anos. No continente americano, países como Honduras, Guatemala e México cultivam o meloeiro visando a exportação aos Estados Unidos, os quais são também grandes produtores e consumidores desta fruta (Shoemaker, 1992). A Europa, a exemplo dos EUA, apresenta um mercado consumidor muito atraente aos produtores brasileiros, principalmente no inverno europeu, quando a oferta da fruta é bem menor.

O Brasil participa como exportador de melão do grupo inodorus, com baixo conteúdo de açúcar, preterido em relação aos melões do grupo reticulatus com conteúdo de açúcar maior e aspecto visual mais atraente. Para a obtenção de frutos de qualidade superior, o melão rendilhado requer condições especiais de cultivo, como casa de vegetação, tutoramento, sistema de condução e poda adequados, informações ainda escassas nas condições brasileiras de cultivo.

A poda melhora a distribuição de seiva na planta, afetando a precocidade, fixação de flores, quantidade, tamanho e maturação de frutos, bem como melhorando as condições para a aplicação de produtos, visando a tratos fitossanitários e adubação foliar (Gómez-Guilamón et al., 1997).

Devido à competição por nutrientes entre órgãos reprodutivos e vegetativos, um determinado estímulo pode induzir ao florescimento, como a retirada de partes da planta por meio da poda. Este mecanismo de desvio de nutrientes das folhas para o fruto, muitas vezes contra o gradiente de concentração, ainda não é bem conhecido, mas provavelmente seja controlado pelo floema, e pela presença de hormônios (Salisbury \& Ross, 1991). Odet (1985) cita que a poda em melão depende de vários fatores que atuam interligados, entre os quais tem-se o tipo varietal, vigor da planta, suprimento de água, fertilidade do solo, sistema de condução e época do ano. Esta interação, segundo o autor, explica os vários resultados contraditórios encontrados na literatura, sobre a melhor ma- neira de se podar. Resultados obtidos por Buitelaar (1985), em casa de vegetação, indicaram que o conteúdo de açúcar em frutos de melão é maior em plantas não podadas, diminuindo proporcionalmente à severidade da poda, sendo que esta variação está relacionada com o híbrido e com a época de plantio.

Mougou et al. (1990) não obtiveram precocidade com poda da haste principal, sendo que a variedade e a densidade de plantio utilizada tiveram maior significância, porém a condução de plantas não podadas resulta em atraso na floração feminina. Marreiros \& Paquete (1995) colocam que a poda de formação em melões do tipo 'Gália' e 'Harvest King', para as condições de Algarve, em Portugal, seria desnecessária, por não se obter precocidade, nem aumento de produção, tendo-se então um ganho na redução da mão-de-obra. Contudo a poda inicial é necessária para forçar o lançamento das hastes secundárias, quando se trabalha com dois ramos tutorados na vertical.

Jaewook et al. (1994) citam que os frutos de plantas conduzidas tutoradas apresentaram maior concentração de sólidos solúveis e maior produção em relação às não tutoradas. Os frutos do $9^{\circ}$ nó apresentaram, ainda, uma maior concentração de sólidos solúveis. Monteiro \& Mexia (1988), em Portugal, trabalhando com melões 'MacDimon' e 'Harvest King', em estufa, verificaram que a quantidade de sólidos solúveis não foi influenciada pelo híbrido, porém 'MacDimon' apresentou maior área foliar.

Neste sentido, este trabalho teve por objetivo verificar o efeito do sistema de condução e posição de fixação do fruto na planta, sobre a produtividade e qualidade dos frutos de dois híbridos de meloeiro.

\section{MATERIAL E MÉTODOS}

O experimento foi conduzido no Distrito de Ibitiúva, região Norte do Estado de São Paulo, de clima tipo Cwa (André \& Volpe, 1992), no segundo semestre de 1998, sendo avaliados os fatores híbridos de Cucumis melo var. reticulatus (Bônus n ${ }^{\circ} 2$ e D. Carlos); sistemas de condução com uma ou duas hastes e posições de fixação dos frutos compreendidas do $5^{\circ}$ ao $8^{\circ}$ nó, do $9^{\circ}$ ao $11^{\circ}$ nó e do $12^{\circ}$ ao $15^{\circ}$ nó, deixando-se sempre duas folhas após o fruto. Cada parcela cons tituiu-se de quatorze plantas, sendo avaliadas as oito plantas centrais para as variáveis do fruto. Utilizouse substrato agrícola, semeando-se em bandejas de poliestireno expandido (128 células), sendo as mudas transplantadas quando apresentavam a primeira folha definitiva e soltavam-se das células da bandeja de isopor sem quebra do torrão, aos 15 dias após a semeadura para 'Bônus $n^{\circ} 2$ ' e aos 18 dias para ' $D$. Carlos'. As plantas foram conduzidas em linha única, no espaçamento de 0,25 $\mathrm{m}$, e $1,25 \mathrm{~m}$ entre fileiras. Independentemente do sistema de condução adotado (uma ou duas hastes), a planta foi conduzida alternando-se uma para a direita e outra para a esquerda na fileira, com orientação do crescimento destas em forma de V. A poda inicial no sistema de condução de duas hastes foi realizada quando a planta possuía quatro a cinco folhas definitivas desenvolvidas, podando-se após a terceira folha e conduzindo-se os dois melhores ramos que brotaram (Nicolas et al, 1989).

As plantas foram tutoradas por uma fita plástica amarrada a um fio de arame rente ao solo e outro fio colocado a 2,0 $\mathrm{m}$ de altura, bem como, por fio de arame colocado paralelamente ao solo à altura de $0,80 \mathrm{~m}$, a fim de auxiliar na sustentação dos frutos, que foram fixados ao arame por rede plástica. Foi procedida a irrigação por gotejamento em dias alternados, ou conforme a necessidade da cultura. As adubações de plantio e cobertura foram realizadas de acordo com Raij et al. (1996) para a cultura do melão, aplicando-se $3,5 \mathrm{~g} /$ planta de sulfato de amônia e $23 \mathrm{~g} / \mathrm{planta}$ de superfosfato simples, com base em análise de solo. Realizaram-se pulverizações com benomyl para prevenção de doenças e de deltamethrine para controle de pragas, quando necessário.

Avaliou-se a matéria seca da parte aérea na floração e por ocasião da colheita, com secagem do material em estufa de circulação forçada de ar (70 $80^{\circ} \mathrm{C}$ ) (duas plantas/parcela/ amostragem), área foliar na floração e por ocasião da colheita (duas plantas/ parcela/amostragem), estimada pelo método de lâminas conhecidas (Benincasa, 
Tabela 1. Média de matéria seca da parte aérea na floração (MSF) e na colheita (MSC) (g/planta), área foliar na floração (AFF) e na colheita (AFC) $\left(\mathrm{m}^{2} /\right.$ planta), número de frutos por planta $(\mathrm{NF} / \mathrm{P})$ e produção total de frutos por planta $(\mathrm{PTF} / \mathrm{P})(\mathrm{kg} / \mathrm{planta})$, em melão rendilhado. Jaboticabal, UNESP, 1998.

\begin{tabular}{llccccc}
\hline \multirow{2}{*}{ Híbridos } & \multicolumn{7}{c}{ Médias } \\
\cline { 2 - 7 } & MSF & MSC & AFF & AFC & NF/P & PTF/P \\
\hline Bônus no 2 & $22,61 \mathrm{~A}^{\text {a/ }}$ & $74,34 \mathrm{~A}$ & $0,3613 \mathrm{~A}$ & $0,7701 \mathrm{~A}$ & $1,15 \mathrm{~A}$ & $1,180 \mathrm{~A}$ \\
D. Carlos & $16,39 \mathrm{~B}$ & $52,48 \mathrm{~B}$ & $0,2550 \mathrm{~B}$ & $0,6094 \mathrm{~B}$ & $0,78 \mathrm{~B}$ & $0,848 \mathrm{~B}$ \\
\hline
\end{tabular}

a Médias seguidas de mesma letra na coluna não diferem entre si, ao nível de 5\% de probabilidade, pelo teste de Tukey.

1988), altura do ponto de fixação do fruto a partir da superfície do solo, espessura do mesocarpo medido na posição central do fruto, conteúdo de sólidos solúveis do suco de uma fatia longitudinal do fruto avaliado com refratômetro manual, massa de frutos pesada em balança eletrônica, número médio de frutos por planta e produção total de frutos por planta. Para análise de variância dos dados utilizou-se delineamento de blocos ao acaso, em esquema fatorial 2 (híbridos) x 2 (sistemas de condução) x 3 (posições de fixação do fruto), com três repetições.

\section{RESULTADOS E DISCUSSÃO}

A análise de variância não indicou interação entre híbridos, sistemas de condução e posições de fixação do fruto para as variáveis matéria seca da parte aérea e área foliar, na floração e por ocasião da colheita, bem como para a espessura do mesocarpo e massa do fruto.

Para o fator híbrido, 'Bônus $\mathrm{n}^{\mathrm{o}} 2$ ' apresentou maiores valores para todas as variáveis (Tabela 1 ), exceto para massa de fruto $(1,07 \mathrm{~kg})$ e espessura do mesocarpo $(3,0 \mathrm{~cm})$ que não apresentaram diferença estatística em relação a 'D. Carlos' (1,065 kg e 2,9 cm). Provavelmente, a maior quantidade de matéria seca da parte aérea na floração (MSF) e colheita (MSC), com maior área foliar em ambos os períodos (AFF e AFC), contribuiu para o maior número de frutos $(\mathrm{NF} / \mathrm{P})$ e produção total por planta $(\mathrm{PTF} / \mathrm{P})$, se comparadas às do híbrido D. Carlos. O rendimento por área também foi maior para híbrido Bônus $\mathrm{n}^{\circ} 2$, com $4,72 \mathrm{~kg} / \mathrm{m}^{2}$, contra $3,39 \mathrm{~kg} / \mathrm{m}^{2}$ para 'D. Carlos', justificável devido ao maior número médio de frutos por planta, uma vez que a massa média de fruto não apresentou diferenças significativas entre os híbridos. Os rendimentos obtidos superaram os de Buwalda \& Freeman

Tabela 2. Média de conteúdo de sólidos solúveis (\%) em função da interação entre híbridos e sistemas de condução em melão rendilhado. Jaboticabal, UNESP, 1998.

\begin{tabular}{lcc}
\hline \multicolumn{1}{c}{ Sistemas de } & \multicolumn{2}{c}{ Híbridos } \\
\cline { 2 - 3 } condução & Bônus $\mathbf{n} \mathbf{2}$ & D. Carlos \\
\hline Uma haste & $14,8 \mathrm{Aa}^{\mathrm{a} /}$ & $10,5 \mathrm{Bb}$ \\
Duas hastes & $15,2 \mathrm{Aa}$ & $12,0 \mathrm{Ab}$ \\
\hline
\end{tabular}

a/ Médias seguidas de mesma letra, maiúscula na coluna e minúscula na linha, não diferem entre si, ao nível de $5 \%$ de probabilidade, pelo teste de Tukey.

(1986) para 'Prince PR' $\left(1,82 \mathrm{~kg} / \mathrm{m}^{2}\right)$ e para 'Tenkei' $\left(2,75 \mathrm{~kg} / \mathrm{m}^{2}\right)$, e também os de Mougou et al. (1990) que obtiveram $2,75 \mathrm{~kg}$ de fruto $/ \mathrm{m}^{2}$ para 'Alpha', porém Monteiro \& Mexia (1988) encontraram valores superiores, com 'Mac Dimon' $\left(6,16 \mathrm{~kg} / \mathrm{m}^{2}\right)$ e 'Harvest King' $\left(4,5 \mathrm{~kg} / \mathrm{m}^{2}\right)$. Esta diferença de produção também foi encontrada por Martins et al. (1998) em melão 'Melina' apresentando maior produção por planta $(1,99 \mathrm{~kg}) \mathrm{em}$ relação ao melão 'Amarelo' (1,55 kg). As diferenças entre os rendimentos apresentados ocorreram principalmente em função dos materiais genéticos utilizados e ambientes diferenciados.

Analisando o fator sistema de condução, as plantas conduzidas com duas hastes apresentaram altura de fixação do fruto $(55,17 \mathrm{~cm})$ significativamente superior às conduzidas com uma haste $(39,50 \mathrm{~cm})$. Este comportamento pode ser explicado pela alteração na relação entre parte aérea e raiz da planta. Geralmente, quando se realiza uma poda na planta, o sistema radicular é capaz de impulsionar o crescimento vegetativo da planta, desviando, desta forma, água e nutrientes para os locais de crescimento (Devlin \& Witham, 1983). Entretanto, Janick (1966) ressalta que algumas partes da planta podem crescer de modo seletivo, o que, segundo Salisbury \& Ross (1991), acontece no caule devido à ação de giberelinas. A poda inicial para a condução da planta com duas hastes pode provocar alongamento dos internódios, associando o crescimento rápido à ação hormonal favorável à atuação de giberelinas.

Não houve diferença estatística entre os dois sistemas de condução com relação ao conteúdo de sólidos solúveis para o híbrido Bônus $\mathrm{n}^{\mathrm{o}} 2$ (Tabela 2). Entretanto, para o melão 'D. Carlos', as plantas conduzidas com duas hastes proporcionaram frutos com conteúdo de sólidos solúveis mais elevado, em relação às plantas conduzidas com uma haste; deste modo, é recomendável para ' $D$. Carlos' a condução em duas hastes visando-se ao acúmulo de açúcar no fruto (Tabela 2).

Independentemente do sistema de condução, 'Bônus n ${ }^{\circ} 2$ ' apresentou maior conteúdo de sólidos solúveis que o híbrido D. Carlos. Esta diferença pode estar associada à precocidade de ciclo deste último (81 dias em média), pois 'Bônus $n^{\circ} 2$ ' mostrou-se mais tardio (98 dias em média), recebendo mais fotossintatos com o fruto retido por mais tempo à planta, de modo semelhante ao que ocorre em frutos com genes inibidores de etileno (Guis et al., 1997). Martins et al. (1998) também encontraram valores maiores de sólidos solúveis $\left(12,4^{\circ}\right.$ Brix) para o híbrido Amarelo (tipo Espanhol), mais tardio do que para o híbrido Melina $\left(9,1^{\circ}\right.$ Brix) tipo Gália. Os resultados encontrados neste experimento conduzem à possível relação po- 
Tabela 3. Produção total de frutos por planta ( $\mathrm{kg} / \mathrm{planta})$ em função da interação entre posições de fixação do fruto e sistemas de condução de melão rendilhado. Jaboticabal, UNESP,

\begin{tabular}{|c|c|c|}
\hline \multirow{2}{*}{ Posições de fixação } & \multicolumn{2}{|c|}{ Sistemas de condução } \\
\hline & Uma haste & Duas hastes \\
\hline 5으 - 8o nó & $0,231 \mathrm{Bb}^{\mathrm{a} /}$ & $0,862 \mathrm{Ba}$ \\
\hline 9으 - 11으 nó & $1,123 \mathrm{Aa}$ & $1,178 \mathrm{Aa}$ \\
\hline 12ㅇ - 15o nó & 1,339 Aa & $1,352 \mathrm{Aa}$ \\
\hline
\end{tabular}

a/ Médias seguidas de mesma letra, maiúscula na coluna e minúscula na linha, não diferem entre si, ao nível de 5\% de probabilidade, pelo teste de Tukey.

sitiva entre duração do estádio de desenvolvimento do fruto, matéria seca acumulada pela planta e área foliar, com conteúdo de sólidos solúveis, uma vez que foram encontrados valores maiores para 'Bônus n' 2' (Tabela 1).

Não se detectaram variações significativas no conteúdo de sólidos solúveis das diferentes posições de fixação do fruto para os híbrido Bônus n ${ }^{\circ} 2$ e D. Carlos, com $12,9 \%, 13,4 \%$ e $13,0 \%$, respectivamente, do $5^{\circ}$ ao $8^{\circ}$ nó, do $9^{\circ}$ ao $11^{\circ}$ nó e do $12^{\circ}$ ao $15^{\circ}$, discordando de Jaewook et al. (1994) que obtiveram maiores concentrações no conteúdo de sólidos solúveis em frutos fixados no $9^{\circ}$ nó. Aparentemente, este acúmulo em determinadas posições da planta pode estar relacionado ao híbrido, uma vez que Sin et al. (1991), na Coréia, encontraram maior conteúdo de açúcar em 'House-Euncheon' do $8^{\circ}$ ao $10^{\circ}$ nó de fixação do fruto em relação às posições do $4^{\circ}$ ao $6^{\circ}$, e do $6^{\circ}$ ao $8^{\circ}$ nó, porém não havendo diferença significativa no conteúdo de sólidos solúveis no híbrido Keumssaragi, em função das várias faixas de fixação testadas. Por outro lado, Nylund (1954), verificando o efeito de desfolha sobre plantas de meloeiro, verificou que plantas com pouca área foliar produziam frutos com menor conteúdo de sólidos solúveis. Monteiro \& Mexia (1988) confirmam uma correlação positiva entre maior área foliar à disposição de cada fruto com o maior conteúdo de sólidos solúveis.

No sistema de condução com uma ou duas hastes, a posição do $5^{\circ}$ ao $8^{\circ}$ nó apresentou menor produção total de frutos por planta para o valor médio de ambos os híbridos, diferindo significativamente das outras duas posições (Tabela 3). Deve-se realizar a fixação do fruto a partir do $9^{\circ}$ nó até o $15^{\circ}$ nó, para uma maior produção e melhor rendi- mento da cultura, facilitando o manuseio dos frutos, uma vez que a fixação e a produção da cultura ficaram prejudicadas com a fixação nas posições mais inferiores.

Em vista dos resultados obtidos, conclui-se que plantas podadas inicialmente e conduzidas com duas hastes apresentam maior altura de fixação do fruto em relação às conduzidas com uma haste sem poda inicial. O híbrido Bônus $\mathrm{n}^{\mathrm{o}} 2$ apresentou maiores índices de conteúdo de sólidos solúveis e rendimento em comparação com o híbrido D. Carlos. O híbrido D. Carlos conduzido com duas hastes apresenta um incremento no conteúdo de sólidos solúveis em relação à condução com uma haste. As diferentes posições de fixação do fruto não influenciaram o conteúdo de sólidos solúveis e massa média do fruto. Frutos fixados do $9^{\circ}$ ao $11^{\circ}$ nó e do $12^{\circ}$ ao $15^{\circ}$ nó apresentaram maior produção total por planta. O híbrido D. Carlos foi mais precoce, porém com conteúdo de açúcar menor em comparação ao híbrido Bônus $n^{\circ} 2$.

\section{AGRADECIMENTOS}

Os autores agradecem à Coordenação de Aperfeiçoamento de Pessoal de Nível Superior (CAPES), pela concessão da bolsa de mestrado do primeiro autor, bem como ao funcionário Welliton I. de Souza, pelo auxílio na condução do experimento na chácara São Luís (Ibitiúva).

\section{LITERATURA CITADA}

ANDRÉ, R.G.B.; VOLPE, C.A. Dados meteorológicos de Jaboticabal no Estado de São Paulo durante os anos de 1971 a 1980. 1982, Jaboticabal, 25 p. (Boletim técnico, 1).
BENINCASA, M.M.P. Análise de crescimento de plantas. Jaboticabal: FUNEP, 1988. 42 p.

BUITELAAR, K. Sugar content of melons. Groenten en fruit, v. 40, n. 45, p. 28-30, 1985.

BUWALDA, J.G.; FREEMAN, R.E. Melons: effects of vine pruning and nitrogen on yields and quality. New Zealand Journal of Experimental Agriculture, v. 14, n. 3, p. 355359, 1986.

DEVlin, R.M.; WITHAM, F.H. Plant Physiology, 1983. 577 p.

GÓMEZ-GUILAMÓN, M.L.; FLORES, R.C.; GONZÁLEZ-FERNANDÉZ, J.J. El melon in invernadero. In: VALLESPIR, A.N. Melones. Barcelona: Ediciones de Horticultura, 1997. p 67-77.

GUIS, M.; BOTONDI, R.; BEN-AMOR, M.; AYUB, B.; BOUZAYEN, M. Ripening associated biochemical traits of cantaloupe charentais melons expressing an antisense accoxidase transgene. Journal of the American Society for Horticultural Science, v. 122, n. 6, p. 748-751, 1997.

JAEWOOK, L.; HANCHUL, R.; CHANGJAE, Y.; KYUCHIL, K.; HWAMO, Y.; LIM, J.W.; RHEE, H.C.; YU, C.J. Effect of fruiting number, fruiting position and training methods on fruit characteristic and quality in melon (cv. Sul Hyang melon). Journal of Agricultural Science, v. 36, n. 2, p. 413417, 1994.

JANICK, J. A ciência da horticultura, Rio de Janeiro: Freitas Bastos, 1966. 485 p.

MARREIROS, A.J.C.; PAQUETE, B.C. A cultura do melão (estufa). Guia do extensionista. Secretaria de Estado da Agricultura de Portugal, Direcção Regional de Agricultura do Algarves, 1995. $62 \mathrm{p}$.

MARTINS, S.R.; PEIL, R.M.; SCHWENGBER, J.E.; ASSIS, F.N.; MENDEZ, M.E.G. Produção de melão em função de diferentes sistemas de condução de plantas em ambiente protegido. Horticultura Brasileira, Brasília, v. 16, n. 1, p. 24-30, 1998.

MONTEIRO, A.A.; MEXIA, J.T. Influência da poda e do número de frutos por planta na qualidade dos frutos e produtividade do melão. Horticultura Brasileira, Brasília, v. 6, n. 1, p. 9-12, 1988.

MOUGOU, A.; VERLODT, H.; DE MUYNCK, B. Influence of different pruning systems on earlness and yield performances of muskmelon under plastic greenhouses. Acta Horticulturae, v. 287 , p. $241-7,1990$.

NICOLAS, M.Z.; FERNANDEZ, P.C.; ARIAS, S.B; MARTINEZ, P.R. El melon. Madrid: Mundi Prensa, 1989. 174 p.

ODET, J. Le melon. França: Ctifl, 1985. 297 p.

RAIJ, B. van; CANTARELLA, H.; QUAGGIO, J.A.; FURLANI, A.M.C. Recomendações de adubação e calagem para o Estado de São Paulo. 2 ed. Campinas: IAC, 1996. 285 p. Boletim 100.

SALISBURY, F.B.; ROSS, C.W. Plant Physiology. 4 ed., Belmont: Wadsworth, 1991. 682 p.

SHOEMAKER, W.H. Melons - Muskmelons, Watermelons, and Honeydews. In: SWIADER, J.M.; WARE, G.W. Producing Vegetable Crops. Illinois: IPP, 1992. p. 361-380.

SIN, GY; HEONG, C.S.; YOO, K.C. Effects of temperature, light intensity and fruit setting position on sugar accumulation and fermentation in oriental melon. Journal of Korean Society for Horticultural Science, v. 32, n. 4, p. 440-446, 1991. 